\title{
Knowledge, Attitude and Self-Care Practice towards Control of Hypertension among Hypertensive Patients on Follow-up at St. Paul's Hospital, Addis Ababa
}

\author{
Dawit Bacha $^{1^{*}, \text { Hailu Abera }}{ }^{1}$
}

\footnotetext{
OPEN ACCESS

Citation: Dawit Bacha, Hailu Abera. Knowledge, Attitude and Self-Care Practice towards Control of Hypertension among Hypertensive Patients on Followup at St. Paul's Hospital, Addis Ababa.EthiopJ Health Sci.2017;29(4):421.doi:http://dx.doi.org/ 10.4314/ejhs.v29i4.2

Received: December 6, 2018

Accepted:May 16, 2019

Published: July 1,2019

Copyright: (C) 2019Dawit Balcha., et al.This is an open access article distributed under the terms of the Creative Commons Attribution License, which permits unrestricted use, distribution, and reproduction in any medium, provided the original author and source are credited.

Funding: St. paul's hospital millennium medical research office

Competing Interests: The authors declare that this manuscript was approved by all authors in its formand that no competing interest exists.

Affiliation and Correspondence:

${ }^{1}$ Cardiology Unit, St. Paul's

Hospital Millennium Medical

College

*Email: daveba98@gmail.com
}

\begin{abstract}
BACKGROUND: Hypertension is the number one cardiovascular risk factor and the leading cause of mortality worldwide. It's the driver of the cardiovascular disease epidemic in Africa where it is a major, independent risk factor for heart failure, stroke and renal failure. There is no study to assess the level of knowledge of hypertension among hypertensive patients in our setup. The objective of this study was to assess knowledge, attitude and selfcare practice towards control of hypertension among hypertensive patients on follow up at our hospital.

METHODS: A total of 385 hypertensive patients who were on follow up at our hospital were randomly selected for interview. The Sociodemographic and relevant clinical data were extracted using a structured questionnaire. Operational definitions and Likert scale was used to compare the variables.

RESULTS: Only 48.6\% of hypertensive patients participated in this study have good basic knowledge of hypertension, $47.8 \%$ of them have good attitude and only $39.5 \%$ of the study participants have good practice towards control of hypertension. Male sex, formal education and being urban resident are associated with better knowledge, attitude and self-care practice of hypertensive patients at our hospital.

Conclusion:

The result states that there is an inadequate knowledge about hypertension; as well attitude and self-care practice towards control of hypertension among our hypertensive patients is generally poor. Responsible bodies should focus on addressing such limitations of hypertensive patients. Attention should be given to hypertensive patients who are females, low educational level and those coming from rural.
\end{abstract}

KEYWORDS:knowledge, attitude, hypertension, hypertensive heart disease, awareness 


\section{INTRODUCTION}

Cardiovascular disease is the leading cause of death in developing countries where it causes nearly as many deaths as HIV, malaria and tuberculosis $(1,2)$. Hypertension is the number one cardiovascular risk factor and the leading cause of mortality worldwide (3). Hypertension is the driver of the cardiovascular disease epidemic in Africa where it is a major, independent risk factor for heart failure, stroke and kidney failure (4). Abundant evidence from randomized controlled trials has shown benefit of antihypertensive drug treatment in reducing important health outcomes in persons with hypertension (5-7). The treatment of hypertension primarily depends on the level of understanding of the patient, the perception an individual has towards hypertension and the magnitude of associated co-morbidities.

According to the Eighth Joint National Committee (JNC 8) on the management of hypertension in adults, hypertension is defined as persistent systolic blood pressure level of $140 \mathrm{~mm} \mathrm{Hg}$ or diastolic blood pressure of $90 \mathrm{~mm} \mathrm{Hg}(8)$. Hypertension is generally classified as primary and secondary on the base of its cause. Primary or essential hypertension is defined when there is no identified cause. The majority, (95\%), of hypertensive patients fall in this category globally(9). A variety of risk factors have been associated with primary hypertension(10). Secondary hypertension is a type of hypertension with an undelying, potentially correctable cause and it contributes to about $5 \%$ of all hypertensive patients (11). Hypertension is associated with a number of serious adverse health effects. The risk begins as the blood pressure rises above $115 / 75 \mathrm{mmHg}$ in all age groups (12-13).

One of the global non-communicable disease targets adopted by the World Health Assembly in 2013 is to lower the prevalence of hypertension by $25 \%$ from its 2010 level by 2025 (14). Hypertension has become a significant problem in many developing countries experiencing epidemiological transition from communicable to non-communicable chronic diseases (15-17). The emergence of hypertension and other cardiovascular diseases as a public health problem in these countries is strongly related to aging of the populations, urbanization, and socioeconomic changes favoring sedentary habits, obesity, alcohol consumption, and salt intake among others $(18,19)$. The global increase in the number of adults with hypertension is a net effect of increase due to population growth and ageing, and decrease due to declining age-specific prevalence (20).

In Ethiopia, even though there are few nationwide studies to evaluatethe magnitude of hypertension, there are regional studies with different prevalence rates. The Ethiopian steps survey on risk factors and prevalence of chronic non-communicable disease done in 2015 revealed the national prevalence of hypertension to be $15.6 \%(21)$

According to a meta-analysis done in 2015, the prevalence of hypertension among Ethiopian populations was estimated to be $19.6 \%$. This study also revealed that prevalence of hypertension is $23.7 \%$ among urban residents and fairly equal between both genders, being $20.6 \%$ in males and $19.2 \%$ in females $(22)$.

Another systematic review revealed that the prevalence of hypertension varies from the highest rate of $31.5 \%$ in males to the lowest rate of $0.8 \%$ in females (23). The prevalence of hypertension in rural areas of Ethiopia was evaluated at different times; one of such investigations done in Bedelle Town, southwest Ethiopia, revealed the prevalence of hypertension to be $16.9 \%$ and showed thatthe awareness of the disease in the same community was low;only $44.8 \%$ of them were aware of their status and only $22.4 \%$ controlled hypertension (24).

An institution based study done on Hawassa University workers revealeda prevalence of $19.7 \%$. This study also looked into knowledge of hypertension and factors affecting knowledge of hypertension whereage, educational level, occupation and monthly income of the participants were significantly associated with better knowledge (25). Self-care practice towards control of hypertension among hypertensive patients has not been studied in our country.

\section{MATERIALS AND METHODS}

This study was conducted from January 1st 2018March 30, 2018 at St. Paul's Hospital Department of Internal Medicine, Cardiology Outpatient Clinic

DOI: http://dx.doi.org/10.4314/ejhs.v29i4.2 
on hypertensive patients on follow-up. The hospital is the second largest public hospital in Ethiopia, which wasbuilt in 1961. The hospital has all major departments with an estimated 1500 staff to provide care to about 250,000 people each year and anestimated catchment population of more than 5 million (26).

This is a hospital based cross sectional study intended to assess the knowledge, attitude and self-care practice towards control of hypertension among hypertensive patients on follow-up at our hospital during the specified study period.The selected hypertensive patients' socio-demographic characters, knowledge, attitude and self-care practices towards control of hypertension were assessed by using pretested structured questioner.

All of the questionnaire were filled by faceface interview with trained data collectors. The questionnaire was divided into four main parts. The first part deals with socio-demographic profiles, co-morbidities and associatedfactors. The second part was meant to assess basic knowledge of hypertension. For each question in this category, score of one (1) for correct response and score of zero ( 0 ) for wrong and 'I don't know' responses were given. At the end, each participant was labeled as having good knowledge of hypertension if he or she scored greater than 4 of 6 $(>66.7 \%)$.

The third part of the questionnairedeals with attitude of the participants towards hypertension in terms of control and management. It has five questions for which a score of one (1) for each correct response and score of zero (0) for each wrong and 'I don't know' responses. Accordingly, participants' attitude towards control of hypertension was labeled good if he or she scoreed more than 3 out of 5 or $>60 \%$.
The last part deals with self-care practice of hypertensive participants concerning control of hypertension. It also involves how the participantsadher to their treatment and actions they take in controlling associated factors. Based on the above operational definition, practice towards control of hypertension is considered to be good practice if an individual has a score of greater than 3 out of 5 or $>60 \%$.

Ethical clearance was obtained from institutional ethical review board. Written consent was obtained from each participant before the interview.

Sample size and sampling technique: Sample size was determined using the single population proportion formula considering the infinite size of the population, $50 \%$ for the unknown prevalence of hypertensive patients with good knowledge, attitude and self-care practice, 5\% margin of error and $95 \%$ confidence interval with estimated nonresponse rate of 5\% making the sample size to be 403. ystematic random sampling technique based on the estimated number of hypertensive patients visiting the clinic was used to select the participants.

\section{RESULTS}

Socio-demographic characteristics and comorbidities: Of the sampled 403 participants, 385 were selected making the response rate to be $95.5 \%$. The mean age of the participants was 57.6 years with the range of 17-85 (SD of 11.9) out of which $54.5 \%$ of them were males.Regarding educational level, $25.2 \%(\mathrm{n}=97)$ of the participants had no formal education while 111(28.8\%) attended college or university as their highest level of educational ( Figure1; Table 1). 


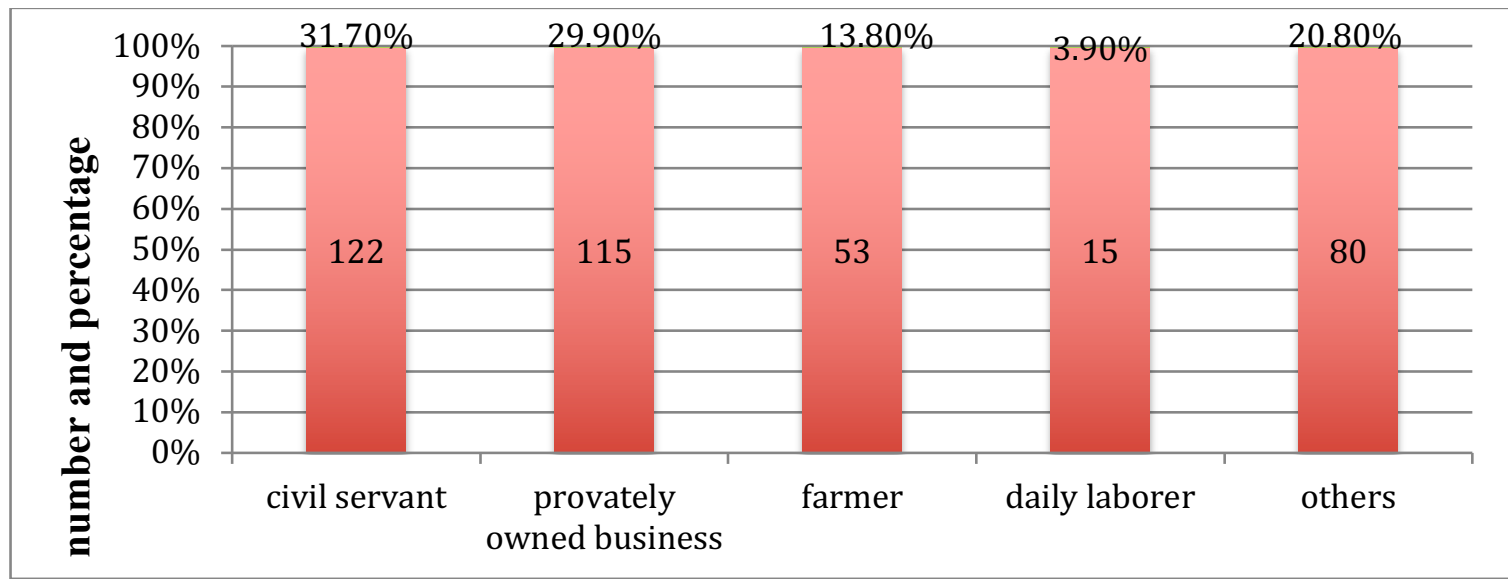

Figure 1:Bar graph showing occupational status of participants

Table 1: Sociodemographic charters of participants

\begin{tabular}{|llcc|}
\hline Variables & & Frequency & Percentage \\
\hline Age groups (years) & $16-25$ & 1 & 0.26 \\
& $26-35$ & 10 & 2.6 \\
& $36-45$ & 48 & 12.5 \\
& $46-55$ & 111 & 28.8 \\
& $56-65$ & 121 & 31.4 \\
& $66-75$ & 69 & 17.9 \\
Gender & $76-85$ & 25 & 6.5 \\
& Total & 385 & 100 \\
Educational level & 210 & 54.5 \\
& Male & 175 & 45.5 \\
& Female & 97 & 25.2 \\
& Completed grades 1-8 & 134 & 34.8 \\
Address & Completed high school & 43 & 11.2 \\
& College/university & 111 & 28.8 \\
Occupation & Total & 385 & 100.0 \\
& Urban & 265 & 68.8 \\
& Rural & 120 & 31.2 \\
& Total & 385 & 100.0 \\
Civil servant & 122 & 31.7 \\
Duration of hypertension (years) & 115 & 29.9 \\
$1-5$ & Privately owned business & 15 & 3.9 \\
$6-10$ & Daily laborer & 53 & 13.8 \\
$11-15$ & Farmer & 80 & 20.8 \\
$16-20$ & & 253 & 65.7 \\
$21-25$ & & 100 & 26.0 \\
$26-30$ & & 20 & 5.2 \\
Total & & 2 & 1.8 \\
& & 385 & 0.52 \\
Others & & 0.78 \\
& & 100 \\
\hline
\end{tabular}

BMI was determined for only 282 participants and making 118 participants $(41.8 \%)$ obese or ranged from $18.7-48 \mathrm{~kg} / \mathrm{m} 2$ of body surface area overweight. Only $50 \%$ of the study participants

DOI: http://dx.doi.org/10.4314/ejhs.v29i4.2 
had identifiable risk factor for hypertensions. Of all participants, $17.7 \%$ drink alcohol,11.4\% had family history of hypertension and 3.6\% were current smokers( see table 2).

Table 2: Risk factors identified among hypertensive patients on follow up at St. Paul's hospital from, January 1st 2018 -March 30, 2018.

\begin{tabular}{lcl}
\hline Risk factors identified & Frequency(n) & Percept \\
Current smoker & 14 & 3.6 \\
Excessive alcohol consumption & 70 & 18.2 \\
Family history of hypertension & 44 & 11.4 \\
Diabetes Mellitus & 54 & 14.1 \\
Kidney disease & 19 & 4.9 \\
Two or more risk factors identified & 17 & 4.4 \\
No risks identified & 193 & 50.1 \\
Total & 385 & 100 \\
\hline
\end{tabular}

Knowledge of hypertension:In this study, only $86(22.3 \%)$ of the participants gave complete right response to knowledge questions, and only $26.2 \%$ (101) of them gave 5 out of 6 correct responses. This indicates, only $187(48.6 \%)$ of participants had good basic knowledge of hypertension.

In this study, multiple variables were found to affect knowledge of hypertension. Males were found to have 2.5 times higher knowledge about hypertension compared to females participants. Age was also another variable affecting participants' knowledge about hypertension. The age group of between 36-45 years had 3.6 times higher knowledge compared to age group of 76-85 years (6.3-19.8 at $95 \%$ ci, SE of 0.29). Level of educational status was directly related to knowledge of hypertension among participants; participants with primary education had 4.3 times higher knowledge; those who completed high school had about 12 times higher knowledge and those who attended college/university had about 16 times higher knowledge compared to those with no formal education. Self-identified urban residents had 11 times higher knowledge compared to rural residents (Table 3).

Table 3: Association of independent variables with knowledge of hypertension of hypertensive patients at St. Paul's hospital, Addis Ababa. January 2018-March 2018.

\begin{tabular}{|l|r|r|r|r|r|r|r|r|}
\hline \multicolumn{1}{|c|}{ Variables } & \multicolumn{1}{|c|}{ B } & S.E. & Wald & df & Sig. & Exp(B) & \multicolumn{2}{c|}{$95 \%$ C.I. for } \\
\cline { 5 - 8 } & & & & & & & & \multicolumn{2}{c|}{ EXP(B) } \\
\cline { 5 - 8 } & & & & & & & Lower & Upper \\
\hline Age & -.003 & .012 & .054 & 1 & .816 & .997 & .975 & 1.020 \\
Sex (male) & .467 & .269 & 3.018 & 1 & .082 & 1.595 & .942 & 2.701 \\
Address (urban) & 2.007 & .318 & 39.887 & 1 & .000 & 7.440 & 3.991 & 13.870 \\
Educational status & & & 21.179 & 3 & .000 & & & \\
Educational status(primary education) & .789 & .374 & 4.444 & 1 & .035 & 2.202 & 1.057 & 4.587 \\
Educational status(high school) & 1.417 & .489 & 8.381 & 1 & .004 & 4.125 & 1.580 & 10.764 \\
Educational status(college/university) & 1.872 & .435 & 18.526 & 1 & .000 & 6.503 & 2.772 & 15.252 \\
Constant & -2.621 & .786 & 11.125 & 1 & .001 & .073 & & \\
\hline
\end{tabular}

In multivariable analysis, urban residence was found to have 7.4 times higher odds of having good knowledge about hypertension compared to rural residence, after adjusting for age, sex and educational status. Similarly, the odds of having good knowledge increased with educational status 
after adjusting for all other variables, but multiple regression analysis didnot show age and sex to be associated with knowledge status of the participants (Table 3 ).

Attitude towards control of hypertension:In the attitude part of the study, only $31(8.1 \%)$ of the participants gave correct response to all attitude questions indicating that only $184(47.8 \%$ ) of the participants to have good attitude about control of hypertension (Table 4). The attitude of participants towards control of hypertension was exceptionally good for salt restriction as correctly responded by $354(91.9 \%)$. Only 166(43\%) of participants thoughtthat excessive alcohol intake worsens blood pressure level.
In univariate analysis, attitude towards control of hypertension is affected by gender making the odds of having good attitude towards control of hypertension two times higher than female participants ( $p$ value of 0.002.). Participants who were urbanresidents had 2.5 times higher odds of having good practice.

All variables,except age, were associated with attitude in the multivariable analysis. Male sex, urban residence and having formal education had twice higher odds of having good attitude of hypertension when adjusted for all other variables compared to female sex, rural residence and having no formal educatio, respectively.

(see table 4).

Table 4: Association of variables to attitude of hypertensive patients at St. Paul's hospital, Addis Ababa, January 2018-March 2018.

\begin{tabular}{|c|c|c|c|c|c|c|c|c|}
\hline \multirow[t]{2}{*}{ Variables } & \multirow[t]{2}{*}{$\mathrm{B}$} & \multirow[t]{2}{*}{ S.E. } & \multirow[t]{2}{*}{ Wald } & \multirow[t]{2}{*}{$\mathrm{df}$} & \multirow[t]{2}{*}{ Sig. } & \multirow[t]{2}{*}{$\operatorname{Exp}(B)$} & \multicolumn{2}{|c|}{$\begin{array}{c}95 \% \text { C.I.for } \\
\text { EXP(B) }\end{array}$} \\
\hline & & & & & & & Lower & Upper \\
\hline Age & -.019 & .010 & 3.323 & 1 & .068 & .981 & .961 & 1.001 \\
\hline Sex (male) & .771 & .244 & 10.001 & 1 & .002 & 2.163 & 1.341 & 3.489 \\
\hline Address (urban) & .899 & .268 & 11.225 & 1 & .001 & 2.458 & 1.452 & 4.160 \\
\hline Educational status & & & 5.131 & 3 & .162 & & & \\
\hline Educational status(primary education) & .727 & .328 & 4.909 & 1 & .027 & 2.070 & 1.088 & 3.939 \\
\hline Educational status(high school) & .704 & .444 & 2.522 & 1 & .112 & 2.023 & .848 & 4.825 \\
\hline Educational status(college/university) & .559 & .386 & 2.105 & 1 & .147 & 1.750 & .822 & 3.725 \\
\hline Constant & -.540 & .688 & .616 & 1 & .433 & .583 & & \\
\hline
\end{tabular}

Table 5: Association of variables with self-care practice of participants towards control of hypertension at St. pauls hospital

\begin{tabular}{|c|c|c|c|c|c|c|c|c|}
\hline \multirow[t]{2}{*}{ Variables } & \multirow[t]{2}{*}{$\mathrm{B}$} & \multirow[t]{2}{*}{ S.E. } & \multirow[t]{2}{*}{ Wald } & \multirow[t]{2}{*}{ df } & \multirow[t]{2}{*}{ Sig. } & \multirow[t]{2}{*}{$\operatorname{Exp}(B)$} & \multicolumn{2}{|c|}{$\begin{array}{l}95 \% \text { C.I. for } \\
\operatorname{EXP}(B)\end{array}$} \\
\hline & & & & & & & Lower & Upper \\
\hline Age & .005 & .011 & .175 & 1 & .676 & 1.005 & .983 & 1.026 \\
\hline Sex (male) & .565 & .254 & 4.941 & 1 & .026 & 1.760 & 1.069 & 2.896 \\
\hline Address (urban) & 1.151 & .302 & 14.580 & 1 & .000 & 3.163 & 1.751 & 5.711 \\
\hline Educational status & & & 16.128 & 3 & .001 & & & \\
\hline $\begin{array}{l}\text { Educational status(primary } \\
\text { education) }\end{array}$ & .512 & .372 & 1.896 & 1 & .169 & 1.669 & .805 & 3.461 \\
\hline Educational status(high school) & 1.454 & .473 & 9.464 & 1 & .002 & 4.281 & 1.695 & 10.814 \\
\hline $\begin{array}{l}\text { Educational } \\
\text { status(college/university) }\end{array}$ & 1.357 & .420 & 10.467 & 1 & .001 & 3.886 & 1.708 & 8.845 \\
\hline Constant & -2.647 & .755 & 12.285 & 1 & .000 & .071 & & \\
\hline
\end{tabular}

DOI: http://dx.doi.org/10.4314/ejhs.v29i4.2 
Self-care practice:In this study, only $31(8.1 \%)$ of the participants had correct response to all questions of this category. The only impressive response by the participants was about adherence to medication and regular follow-up for hypertension, which is correctly answered by 374 (97.1\%). Overall, only $152(39.5 \%)$ of the study participants had good practice of control of hypertension.

As part of the self-care practice, the participants' last eye examination was assessed, and only $79(20.6 \%)$ of the patients had eye examination within the last one year. That is considered good practice according to our operational definition.

Like both knowledge and attitude, multiple variables were found to affect the practice of participants towards control of hypertension. Males had 1.76 times higher odds of having good practice compared to females ( $p$-value 0.02). Being urban resident was associated with a 3 times higher odds of having good practice compared to rural residence. Educational status was another variable found to affect self-care of hypertensive participants.

In univariate analysis,participants who completed high school had 4 times higher odds of having good practice and those who attendedcollege/university had 3.8 times higher odds of having good practice compared to those with no formal education. There was no significant difference between participants with no formal education and who attended primary school in terms of their attitude towards hypertension.

In multivariable logistic regression, males had about twice odds of performing good practice compared to females [AOR: $(95 \% \mathrm{CI})=1.76$ $(1.07,2.90)]$. Urban residents had three times higher odds of good practice compared to rural residents [AOR: $(95 \% \mathrm{CI})=3.20(1.80,5.71)]$. The odds of good practice also increased with educational level; those with no formal education havdapoor hypertension control practice (Table 5)

\section{DISCUSSION}

\footnotetext{
DOI: http://dx.doi.org/10.4314/ejhs.v29i4.2
}

This hospital based cross sectional study was intendedto assess knowledge, attitude and selfcare practice among hypertensive patients on follow-up.Accordingly, the overall basic knowledge about hypertension of hypertensive patients in our hospital was low; less than $50 \%$ of the participants had good knowledge.The knowledge of hypertensive patients about their disease varies from county to country and from region to region of the same country. Previous studies showed conflicting reports about knowledge of hypertension among hypertensive patients. One of such was in Karachi, Pakistan, which showed that $81.1 \%$ of study participants did not know hypertension (27).

In another review done in the United States, it was found that $81.0 \%$ of the participants knew the definition of hypertension, but $35 \%$ of them did not consider high BP as a serious health concern while over $35 \%$ believed that high BP is unavoidable. In this study, the investigators were interested in patients' perception of BP levels as compared to actual BP as recorded in the medical recordexplored the relationship between patient self-report of BP levels and actual values recorded in the medical record at the last visit.

Forty-one percent of them did not know their BP values(28). In this study, the factorassociated with better knowledge of hypertension was found to be educational level of the participants. Participants who completed high school reported better understanding of hypertension than patients without high school education (28).

In Ethiopia, there are few studies that tried to look into knowledge of hypertension among hypertensive patients. One of such studies, done in western part of the country, showed that only $44.2 \%$ of the hypertensive patients involved in that study were aware of their hypertensive status, and that only $22.4 \%$ of those on treatment had their blood pressure controlled (24).Even in regions of the world where there is better general knowledge of hypertension, patients lack comprehensive understanding. This has been noted in a review done on 1250 hypertensive patients in the United Stateswhere patients do not recognize the importance of elevated systolic blood pressure 
levels or the current status of their blood pressure control (28). Similarly, in our study, age, sex, educational level, and address were strongly related with better knowledge of hypertension among hypertensive patients but not with duration of hypertension. Males were found to have 2.5 times higher knowledge compared to females who were involved in this study, and the age groups of between 36-45 years had3.6 times higher knowledge compared to the age groups of 76-85 years. Educational status was directly related to knowledge of hypertension in this study.

Attitude of participants towards control of hypertension was poor in this study; only $47.8 \%$ of them had good attitude towards control of hypertension. This is also consistent with previous findings from many reports of hypertensive patients around the world. One of such reviews is from Nigeria where attitude towards control of hypertension was found to be very low. Less than $25 \%$ of the study participants had good attitude towards control of hypertension and other associated factors (29). A nationwide telephone survey done in Malaysiain the year 1999 also showed that the attitude of hypertensive patients towards control of hypertension either by using medication or non-pharmacologic approach was low (30).

In the self-care practice of hypertensive patients, drug adherence stands at far front in terms of controlling hypertension and hence possibly preventing long term complications related to hypertension. In our study, we found that self-care practice of study participants towards control of hypertension was low; only $39.5 \%$ of the participants had good self-care practice towards control of hypertension. Specifically, adherence to medications for hypertension and regular follow-up were found to be unexpectedly good $(97 \%$ of participants have good regular follow up). Regular exercise as a practice of controlling hypertension was poor as reported to be practiced only by $46 \%$ of the participants.

In conclusion, this study revealed that hypertensive patients on follow-up at our hospital had poor basic knowledge about hypertension, poor attitude and self-care practice towards control of hypertension. We would like to recommend that health professionals actively involved in the management of hypertensive patients need to understand the overall poor knowledgeofhypertensionamong hypertensive patients in our setup. Special attention should be given tofemale gender, low educational level and those coming from rural areas in giving support on hypertension related knowledge and attitude towards hypertension. Works on awareness of hypertension and practice towards control of hypertension need to be advocated in our hospital. Thus, opportunity exists to focus on patient education programs and interventions on the cardiovascular risk associated with uncontrolled hypertension.

The strength of this study is that it is the first of its type to be conducted in our institution looking into the knowledge and attitude of hypertensive patients towards their disease. However, it has some limitations that might make generalization difficult. One of such limitations is that it was done in one institution only which is a referral center to which atients with difficulyto control or other comorbidities are referred; these might not represent all hypertensive patients.

\section{ACKNOWLEDGMENTS}

We would like to thank SPHMMC research office for the financial support. We are also thankful to our participants for giving us their time during the evaluation

\section{RFERENCES}

1. Gaziano TA: Cardiovascular disease in the developing world and its cost effective management.Circulation 2005, 112(23):35473553.

2. Lopez AD, Mathers CD, Ezzati M, Jamison DT, Murray CJL: Global and regional burden of disease and risk factors: systematic analysis of population health data. Lancet 2006, 367(9524):1747-1757.

3. Lawes CM, Vander HS, Rodgers A. Global burden of blood-pressure-related disease, 2001. Lancet. 2008; 371:1513-8.

4. Brundtland GH: The World Health Report 2002: reducing risks, promoting healthy life. Geneva: World Health Organization; 2002. 
5. Staessen JA, Fagard R, Thijs L, et al. The Systolic Hypertension in Europe (Syst-Eur) Trial Investigators.Lancet.1997; 350(9080):757-764.

6. Beckett NS, Peters R, Fletcher AE, et al. HYVET Study Group. Treatment of hypertension in patients 80 years of age or older. $N$ Engl J Med. 2008; 358(18):18871898.

7. SHEP Cooperative Research Group. Prevention of stroke by antihypertensive drug treatment in older persons with isolated systolic hypertension: final results of the Systolic Hypertension in the Elderly Program (SHEP). JAMA. 1991; 265(24):3255-3264.

8. Paul A. James, Suzanne Oparil, Barry L. Carter, Pharm et al. JAMA 2014; 311(5):507520

9. Staessen JA, Wang J, Bianchi G, Birkenhäger WH. Essential hypertension. Lancet 2003; 361:1629

10. Burgaz A, Orsini N, Larsson SC, Wolk A. Blood 25-hydroxyvitamin D concentration and hypertension: a meta-analysis. $J$ Hypertension 2011; 29:636.

11. Kaplan NM. The sixth report of the Joint National Committee on prevention, detection, evaluation, and treatment of high blood pressure. Arch Intern Med 1997; 157:2413.

12. Jackson R, Lawes CM, Bennett DA, et al. Treatment with drugs to lower blood pressure and blood cholesterol based on an individual's absolute cardiovascular risk. Lancet 2005; 365:434

13. DANAEI, Goodarz; LU, Yuan et al. Global Burden of Metabolic Risk Factors for Chronic Diseases Collaboration. Cardiovascular disease, chronic kidney disease, and diabetes mortality burden of cardio metabolic risk factors from 1980 to 2010: a comparative risk assessment. Lancet Diabetes Endocrinol 2014; 2: 634-47.

14. WHO. Global action plan for the prevention and control of non-communicable diseases 2013-2020. 2013. http://apps.who.int/ iris/ bitstream/ 10665/ 94384/ 1/9789241506236_eng.pdf? Ua=1
15. Dodu S.R.A. Emergence of cardiovascular diseases in developing countries. Cardiology. 1988; 75:56-64.

16. Nissinen A, Bothig S, Granroth H, Lopez AD. Hypertension in developing countries. World Health Stat Q. 1988; 41:141-154.

17. World Health Organization. Cardiovascular diseases in developing countries. World Health Stat Q. 1993; 46:90 -150.

18. Omran AR. The epidemiological transition: a theory of the epidemiology of population change. Milbank Memorial Fund Quarterly. 1971; 4:509-538.

19. Akinkugbe OO. World epidemiology of hypertension in blacks. $J$ Clin Hypertension 1987; 3:1S-8S.

20. Majid E. Worldwide trends in blood pressure from 1975 to 2015. The lancet. 2017;7(389)

21. YeweyenharegFelekeGebreyes, Dejuma Yadeta Goshu, TedlaKebedeGeletew, et al. Magnitude of metabolic risk factors of cardiovascular disease: national NCDs STEPS Survey2015. PLOS ONE 13(5): e0194819.https://doi.org/10.1371/journal

22. Kibret, Mesfin. Prevalence of hypertension in Ethiopia: a systematic meta-analysis, Public Health Reviews 2015 36:14.

23. Molla M. Systematic Reviews of Prevalence and Associated Factors of Hypertension in Ethiopia: Finding the Evidence, Science Journal of Public Health 2015; 3 (4): 514-519

24. FeyieBonsa, EsayasKebedeGudina, KifleWoldemichaelHajito.Prevalence of hypertension and associated factors in Bedelle town, southwest Ethiopia, Ethiop $J$ Health Sci. 2014 Jan; 24(1): 21-26.

25. AtkiltEsaiyas, TesfayeTeshome, DejeneKassa. Journal of Vascular Medicine \& Surgery; 2018; 6:354

26. Belay Alemayehu: Medical Services. Accessed online from official website of SPHMMC on June1 8, 2016.

27. Muhammad Bilal, Abdul Haseeb, SehanSirajLashkerwala, et.al. Knowledge, awareness and self care practice of hypertension among cardiac hypertensive patients. Global Journal of Health Science 2016; 8(2): 9-19.

DOI: http://dx.doi.org/10.4314/ejhs.v29i4.2 
28. Susan A Oliveria, Roland S Chen, Bruce D McCarthy, et al. Hypertensionknowledge, awareness and atittude in hypertensivepopulation.J Gen internmed 2005; 20:219-225.

29. SaiduHadiza, Ahmad MaifadaYakasai, Jamila Ado Yau, Fatima IdrisAdamu, Muhammad SaniMijinyawa.Factor analysis of knowledge, attitude and practice of life style modification measures among hypertensive patients in North - Western Nigeria.J. Med. Res. 2017; 3(2):74-78.

30. K L Khoo,Y M Liew,HTan,J S Sambhi,B A Hatijahpatients knowledge and attitude towards treatment and control of hypertension:
A nation-wide telephone survey conducted in Malaysia. Med J Malaysia 1999; 54 (1): 3746.

DOI: http://dx.doi.org/10.4314/ejhs.v29i4.2 